\title{
UTILIZAÇÃO DE MICROONDAS NA AVALIAÇÃO DA BIOMASSA MICROBIANA DO SOLO ${ }^{(1)}$
}

\author{
A. S. FERREIRA ${ }^{(2)}$, F. A. O. CAMARGO ${ }^{(3,4)} \&$ C. VIDOR $^{(3)}$
}

\begin{abstract}
RESUMO
O presente trabalho teve por objetivo determinar o carbono e o nitrogênio presentes na biomassa mi crobiana, usando a irradiação do forno de microondas em substitui ção ao clorofórmio nos métodos fumi gação-incubação e fumigaçãoextração. Foram utilizadas duas amostras de um Podzólico Vermelho-E scuro, submetidas aos procedimentos de incubação e de extração, após serem fumigadas com clorofór mio e irradiadas com microondas por diferentes períodos $(2,5,10$, $15,20,30,40$ e $50 \mathrm{~min}$ ). Observou-se que a irradiação durante $2 \mathrm{~min}$ foi suficiente para estimar o C e o $\mathrm{N}$ presentes na biomassa microbiana nos procedimentos de incubação e extração, com valores semelhantes aos verificados pela fumigação com clorofórmio. A irradiação com mi croondas reduziu os coeficientes de variação nas amostras de solo submetidas ao procedimento de extração, comprovando ser o método irradiação-extração o mais adequado para a estimativa do $\mathbf{C}$ e do $\mathbf{N}$ microbianos.
\end{abstract}

Termos de indexação: C e N microbianos, incubação, extração, método.

\section{SUMMARY: USE OF MICROWAVE RADIATION TO EVALUATE SOIL MICROBIAL BIOMASS}

The objective of this work was to determine carbon and nitrogen content in the soil microbial biomass by comparing microwave radiation and chloroform fumigation using theextraction and incubation methods. Two soil samples (Dark-Red Podzolic) weresubmitted to incubation and extraction after chloroform fumi gation and mi crowaveradiation during different periods $(2,5,10,15,20,30,40$ and $50 \mathrm{~min})$. Two minutes under mi crowaveradiation were sufficient to determine $\mathrm{C}$ and $\mathrm{N}$ content in the soil biomass using incubation and extraction procedures. Theseval ues weresimi lar to thoseobtained by chloroform fumigation. Thecoefficients of variation in thesoil samples submitted to microwaveradiation extraction werereduced. Thus, this was consider ed themost adequateprocedurefor carbon and nitrogen quantification in soil biomass.

Index terms: microbial $\mathrm{C}$ and $\mathrm{N}$, incubation, extraction, method.

(1) Recebido para publicação em junho de 1998 e aprovado em junho de 1999.

(2) Engenheiro-Agronômo do Departamento de Solos, Universidade Federal do Rio Grande do Sul - UFRGS. Caixa Postal 776, CEP 90001-970 Porto Alegre (RS).

(3) Professor Adjunto do Departamento de Solos, UFRGS.

(4) Bolsista do CNPq. Email: fcamargo@ufrgs.br. 


\section{NTRODUÇÃO}

Um dos métodos mais utilizados na determi nação da bi omassa do sol o está baseado na sua fumigação com clorofórmio. Entretanto, esse reagente não é eficiente como biocida para alguns microrganismos (J enkinson \& Powlson, 1976; Kassin et al., 1981), além de difícil obtenção comercial. Desse modo, torna-se necessário um método queaproveite mel hor os recursos existentes nos laboratórios de microbiologia. Destaca-se, neste caso, o uso do forno de microondas como uma alternativa para a substituição do clorofórmio na eliminação dos microrganismos do solo, princípio este utilizado na determinação da biomassa microbiana do solo (J enkinson \& Powlson, 1976).

A atuação do forno de mi croondas na eliminação de microrganismos é resultado da quantidade de irradiação el etromagnética a ser admi nistrada, visto que os níveis têm efeito na transferência de energia e na temperatura, rompendo a parede celular e, conseqüentemente, liberando o material citoplasmático para a solução do sol o. Em termos de sensibilidade, a população de fungos, em razão da sua constituição e do tamanho das hifas, é mais exposta e, com isto, mais afetada pelas microondas do quea população de bactérias (Vance et al., 1987). Neste caso, é necessária a avaliação da quantidade de energia atuante sobre a biomassa ou, especificamente, sobre os grupos microbianos. Além da quantidade de energia irradiada, deve ser considerado o tempo de exposição das amostras à radiação, pois este pode afetar o material orgânico não proveniente dos microrganismos e, com isto, superestimar os valores de biomassa microbiana (Zagal, 1989; Puri \& Barraclough, 1993).

Com base nessas considerações, o presente trabal ho teve como objetivo estimar o carbono e nitrogênio presentes na bi omassa mi crobiana do solo, utilizando o forno de mi croondas em substituição ao clorofórmio nos métodos fumigação-extração e fumigação-incubação.

\section{MATERIAL E MÉTODOS}

Duas amostras de Podzólico Vermelho-Escuro, provenientes de campo nativo e de solo cultivado, foram coletadas na Estação Experimental Agronômica da UFRGS na profundidade de $0-5 \mathrm{~cm}$. As amostras foram peneiradas $(2 \mathrm{~mm})$, mantidas com a umidade do momento da coleta e colocadas sob refrigeração $\left( \pm 4^{\circ} \mathrm{C}\right)$ até o momento de suas análises. Utilizaram-se duas amostras: a primeira, para realizar testes preliminares com o objetivo de sel ecionar o tempo de irradiação, e a segunda, para definir o método e o procedimento mais adequado para estimar oC eoN microbianos a partir do tempo selecionado.
Retiraram-se subamostras em triplicatas da primeira amostra para oteste preliminar, composto dos seguintes tratamentos: (a) sol o sem fumigação e sem irradiação; (b) sol o fumigado com cl or ofórmio; e (c) solo irradiado com microondas. Nesta fase, os tempos de irradiação utilizados foram de 5, 10, 15, $20,30,40$ e $50 \mathrm{~min}$. No segundo teste, utilizaram-se subamostras (em quadruplicatas) submetidas aos tempos de 2, 5, 10 e 15 min. Em todas as fases, foi determi nada a umidade das amostras pela diferença de peso antes edepois da irradiação com mi croondas.

Utilizou-se o forno de microondas da marca Sanyo Prosdócimo, modelo EM 9003 B, tensão de alimentação $120 \mathrm{~V}(60 \mathrm{~Hz})$, freqüência de microondas de $2.450 \mathrm{MHz}$ e concentração de energia $1,35 \mathrm{KW}$. Essas informações foram utilizadas para calcular a quantidade de energia emitida em função do tempo de irradiação ( ) ). Este val or foi obtido por meio da fórmula $\mathrm{T}=\mathrm{P} \Delta \mathrm{t}$, em que $\mathrm{T}=$ trabalho, energia; ou: $\mathrm{P}=$ potência $=\mathrm{W}=\mathrm{J} \mathrm{s}^{-1} ; \mathrm{t}=$ tempo; $\operatorname{logo} T=\mathrm{J} \mathrm{s}^{-1} \Delta \mathrm{t}(\mathrm{s})=\mathrm{J}$. Então, com a potência de $1350 \mathrm{w}$ e um tempo de $120 \mathrm{~s}$, obteve-se 1,62 105 J . Na ausência de dados de potência, pode-seutilizar a fórmula $P=U^{2} R^{-1}$, em queU =voltagem do aparel ho (120 ou 220 V) e R = resistência (W). Este cál cul o foi feito para padronizar o método e possibilitar a utilização de qualquer aparel ho que disponha das informações acima descritas.

Porções de $40 \mathrm{~g}$ de sol o foram col ocadas em frascos (100 mL) para serem submetidas à fumigação com clorofórmio e à irradiação. Para a fumigação, adicionaram-se $4 \mathrm{~mL}$ de $\mathrm{CHCl}_{3}$ (isento deetanol) aos frascos que permaneceram fechados sob fumigação em sala de incubação mantida no escuro, com temperatura controlada a $28^{\circ} \mathrm{C}$, sendo $0 \mathrm{CHCl}_{3}$ removido por aspirações sucessivas após $24 \mathrm{~h}$ de incubação. As demais porções desolo foram col ocadas em placas de Petri e esterilizadas no forno de microondas, sendo determinada nestas amostras a umidade pela diferença de peso antes e depois da esterilização. O tratamento-controle diferenciou-se dos demais por não submeter as porções de solo à fumigação ou à irradiação. Deste procedimento resultaram o método fumigação-extração $(F E)$ e o método irradiação-extração (IE ).

Adicionaram-se aos frascos $50 \mathrm{~mL}$ de $\mathrm{K}_{2} \mathrm{SO}_{4}$ $0,5 \mathrm{~mol} \mathrm{~L}^{-1}$, utilizando uma relação solo:extrator 1:1,25 (Vance et al., 1987), seguido de agitação por meia hora e de filtragem em fil tro médio. Da solução filtrada, retirou-seuma alíquota de $25 \mathrm{~mL}$ do extrato para a determinação do carbono orgânico (Tedesco et al., 1995). O nitrogênio da biomassa foi extraído com o mesmo extrator a partir da relação solo:extrator 1:1,25 e 1:2 para os procedimentos de extração e de incubação, respectivamente, utilizando uma alíquota de $5 \mathrm{~mL}$ da solução filtrada para determinação do nitrogênio total (Tedesco et al., 1995). 
Para o método fumigação-incubação $(\mathrm{FI})$ e o irradiação-incubação (II) foram realizados os mesmos procedimentos supradescritos, diferindo pela inoculação de $2 \mathrm{~g}$ de solo nas amostras fumigadas e nas irradiadas. Em seguida, procedeuse à incubação, durante 10 dias, nas mesmas condições do procedimento de extração. Cada amostra foi incubada em frascos de $1 \mathrm{~L}$, hermeticamente fechados, providos de recipientes com $10 \mathrm{~mL}$ de $\mathrm{NaOH} 1 \mathrm{~mol} \mathrm{~L}^{-1}$ para captação do $\mathrm{CO}_{2}$ liberado. $\mathrm{O}$ controle diferenciou-se dos demais por não submeter as amostras de solo à fumigação e à irradiação. Após a incubação, os recipientes com $\mathrm{NaOH}$ foram retirados e receberam $5 \mathrm{~mL}$ de $\mathrm{BaCl}_{2}$ $1 \mathrm{~mol} \mathrm{~L}^{-1}$ e algumas gotas de fenolftaleína para titulação com HCl 1 mol L-1 padronizado. A liberação do $\mathrm{CO}_{2}$ foi calculada pela fórmula (Stotzky, 1965):

$$
\mathrm{mg} \mathrm{CO} 2=(\mathrm{B}-\mathrm{V}) \cdot \mathrm{M} \cdot \mathrm{E}
$$

em que $\mathrm{B}=$ volume de $\mathrm{HCl}$ necessário para titular o excedente de $\mathrm{NaOH}$ da prova em branco; $\mathrm{V}=$ volume de $\mathrm{HCl}$ necessário para titular o excedente de $\mathrm{NaOH}$ da amostra; $\mathrm{M}=$ molaridade do $\mathrm{HCl} 1 \mathrm{~mol} \mathrm{L-1}$; $\mathrm{E}=$ peso equivalente do carbono.

Os valores do carbono presente na biomassa microbiana foram calculados pela equação descrita a seguir:

$$
\mathrm{C}_{\text {mic }}=\left(\mathrm{C}_{\mathrm{Fl}}-\mathrm{C}_{\mathrm{NFI}}\right) / \mathrm{K}_{\mathrm{C}}=\mu \mathrm{g} \mathrm{g}-1 \text { de } \mathrm{C} \text { no solo }
$$

em que $\mathrm{C}_{\text {mic }}=$ carbono presente na biomassa microbiana do sol o; $\mathrm{C}_{\mathrm{FI}}=$ carbonopresentena amostra fumigada ou irradiada; $\mathrm{C}_{\mathrm{NFI}}=$ carbono presente na amostra não fumigada ou não irradiada; $K_{C}=$ fator de conversão de 0,33 (Sparling \& West, 1988), para o método FE ou IE, e de 0,45, para o método F I ou I I (De-Polli \& Guerra, 1996).

O cálculo do nitrogênio presente na biomassa ( $\mu \mathrm{g} \mathrm{g}^{-1}$ de $\mathrm{N}$ no solo) foi efetuado seguindo o mesmo princípio descrito na equação anterior, diferindo apenas pelo uso de $K_{N}$ de 0,54 (Brookes et al., 1985), para os métodos fumigação-extração $(F E)$, irradiação-extração (IE), fumigação-incubação (FI) e irradiação-incubação (II).

O delineamento experimental foi de blocos ao acaso e os resultados foram submetidos à análise de variância, à comparação de médias, às análises de correlação e de regressão descontínua e à determinação dos intervalos de confiança.

\section{RESULTADOS E DISCUSSÃO}

O carbono da biomassa apresentou, no ensaio preliminar, valores crescentes com o tempo de irradiação até 15 min (Quadro 1), a partir do qual os val ores nãoaumentaram significativamente. Além disso, $15 \mathrm{~min}$ foi o tempo determinado através de regressão descontínua como suficiente para o tratamento das amostras com irradiação de microondas para avaliação da biomassa pelos métodos de extração $\left(R^{2}=0,89\right)$ ou incubação $\left(R^{2}=0,87\right)$. Observou-se que, a partir deste tempo, a solução extraída apresentava uma coloração amarel o-esverdeada, produzida provavel mente, pela alteração do carbono orgânico não-microbiano do solo. Observou-se, ainda, que o coeficiente de variação obtido pel o método fumi gação-extração foi menor em comparação com o da incubação, demonstrando maior precisão nos valores determinados.

O carbono microbiano estimado pelo método irradiação-extração foi superior ao observado pelo métodoirradiação-incubação (Quadro 1), verificandose o contrário para o método utilizando cl orofórmio, resultados esses concordantes com os obtidos por Lovell et al. (1995). Entretanto, segundo vários autores, odorofórmi oreduz apenas parteda população microbiana responsável pela mineralização da matéria orgânica (Shiel ds et al., 1974; J enkinson \& Powlson, 1976; Kassin et al., 1981), principalmente a população de fungos (Kassin et al., 1981). Deste modo, os val ores observados para o C microbiano no método fumigação-incubação podem ter sido produzidos pela atividade bacteriana sobre a degradação da biomassa fúngica, uma vez que estes foram eliminados mais eficientemente pelo clorofórmio. Não obstante, o período de incubação de 10 dias favorece o estabelecimento dos grupos bacterianos, pois estes possuem maiores taxas de crescimento comparadas às dos demais grupos microbianos do solo.

\section{Quadro 1. Carbono e nitrogênio microbianos do solo determi nados pel os métodos de irradiação e de fumigação, utilizando os procedimentos

\begin{tabular}{|c|c|c|c|c|}
\hline \multirow{2}{*}{ Tratamento } & \multicolumn{2}{|c|}{ Carbono } & \multicolumn{2}{|c|}{ Nitrogênio } \\
\hline & Extração & Incubação & Extração & Incubação \\
\hline \multirow[t]{2}{*}{$\min$} & \multicolumn{4}{|c|}{$-\mu \mathrm{g} \mathrm{g}^{-1}$ de C no solo } \\
\hline & \multicolumn{4}{|c|}{ Irradiação } \\
\hline $\begin{array}{r}5 \\
10 \\
15 \\
20 \\
30 \\
40 \\
50\end{array}$ & $\begin{array}{c}488 c \\
954 b c \\
1327 a b \\
1354 a b \\
1539 a \\
1493 a \\
1454 a\end{array}$ & $\begin{array}{l}282 b \\
525 a b \\
807 a \\
888 a \\
706 a b \\
707 a b \\
646 a b\end{array}$ & $\begin{array}{c}74 c \\
98 b c \\
122 a b \\
138 a b \\
153 a \\
160 a \\
140 a b\end{array}$ & $\begin{array}{l}24 \mathrm{~d} \\
48 \mathrm{~cd} \\
60 \mathrm{~cd} \\
85 c \\
167 \mathrm{ab} \\
194 \mathrm{a} \\
132 \mathrm{~b}\end{array}$ \\
\hline 50 & \multicolumn{4}{|c|}{ Fumigação } \\
\hline Fumigado & 238 & 403 & 122 & 52 \\
\hline C.V. (\%) & 12,9 & 20,4 & 13,4 & 13,9 \\
\hline
\end{tabular} de extração e de incubação}

Médias seguidas de letras iguais, na coluna, não diferem estatisticamente entre tratamentos, pelo teste de Tukey a 5\%. 
Os val ores denitrogênio estimados pela extração, tanto no método de fumigação como no de irradiação, foram, em média, 3,1 e 2,3 vezes superiores aos do procedimento de incubação, respectivamente (Quadro 1). A correlação observada entre o carbono e o nitrogênio microbiano estimado pelo método irradiação-extração foi significativamente superior $(r=0,95 ; p<0,05)$ ao estimado pelo método irradiação-incubação $(r=0,43 ; p<0,05)$.

Os valores da biomassa microbiana do solo (expressos em C), avaliados no segundo ensaio e obtidos após irradiação com microondas, situaramse entre 249 e $650 \mu \mathrm{g} \mathrm{g}^{-1}$ de $\mathrm{C}$ no solo, quando se procedeu à extração, e 151 a $699 \mu \mathrm{g} \mathrm{g}^{-1}$ de C no solo para o procedimento de incubação (Quadro 2). Verificou-se que os coeficientes de variação (C.V.) encontravam-se em níveis aceitáveis, quando foi utilizado o método irradiação-extração, ao passo que se mostraram elevados, quando utilizado o método irradiação-incubação.

A correlação positiva $(r=0,90 ; p<0,05)$ verificada entre o carbono mi crobiano estimado pelo método irradiação-incubação e o carbono extraído pelo método irradiação-extração demonstra que os dois métodos estimam compartimentos de carbono semel hantes no solo. Observou-se, ainda, que os valores obtidos pelo método irradiação-extração superaram os de irradiação-incubação, em média de $37 \mu \mathrm{g} \mathrm{g}^{-1}$ de $C$ no solo.

Os resultados apresentados no quadro 2 demonstram que os valores de biomassa microbiana determinados após 2 min de irradiação com microondas foram semelhantes aos da fumigação com clor ofórmio, tanto no procedimento de incubação como no de extração. Nesse período de exposição (2 min), observou-se que o método irradiaçãoextração apresentou os menores coeficientes de variação e intervalos de confiança, quando comparado aos obtidos com o método fumigaçãoextração, demonstrando, assim, por este método, maior grau de precisão e confiabilidade nos valores estimados de carbono microbiano.

Outro aspecto a ser abordado seria em relação ao número de subamostras de solo utilizado na quantificação da biomassa microbiana do solo. Os resultados demonstram quenão haveria necessi dade de mais do que três subamostras, quando se utiliza o método irradiação-extração, para seobter bom grau de precisão, considerando as semel hanças entre os coeficientes de variação e o intervalo de confiança (Quadro 2). Por outrolado, para o método irradiaçãoincubação, seria aconsel hável maior número de subamostras para se atingir amplitude dos valores de biomassa microbiana, uma vez que esseaumento não se refletiu em diminuição do coeficiente de variação, que se manteve alto, independentemente do número de subamostras. Os baixos coeficientes de variação verificados nas amostras não fumi gadas enão irradiadas (Quadro 2) indicam ser conveniente diminuir o número de subamostras para não mais do que duas, proporcionando, desse modo, maior praticidade nas análises dos experimentos que envolvam a estimativa da biomassa microbiana.

A intensidade de energia a que o solo irradiado pelas microondas foi exposto no presente trabalho foi, aos $2 \mathrm{~min}$, de 1,62 $105 \mathrm{~J}$. Este valor é preponderante na eficiência da análise, pois os grupos microbianos são afetados de forma diferenciada pela quanti dade de irradiação a que são submetidos. Em geral, os níveis de $2,010^{4} \mathrm{~J}$ a $1,2105 \mathrm{~J}$ reduzem significativamentea população de fungos, chegando, em níveis mais elevados, à eliminação total desse grupo microbiano (Zagal, 1989). No entanto, as bactérias apresentam maior resistência às microondas, necessitando de quantidades mais el evadas de energia para que haja redução significativa (Vela et al., 1976; Wainwright et al., 1980). Esses mesmos autores observaram que a exposição a $1,2105 \mathrm{~J}$ reduz grande parte da população bacteriana, mas a 4,8 $105 \mathrm{~J}$, foram ainda detectadas al gumas células viáveis no solo.

Quadro 2. Carbono presente na biomassa microbiana, com os respectivos intervalos de confiança (95\%), determinado pelos métodos de fumigação e de irradiação, utilizando os procedimentos de extração e de incubação

\begin{tabular}{|c|c|c|c|c|c|c|}
\hline & \multicolumn{3}{|c|}{ Extração } & \multicolumn{3}{|c|}{ Incubação } \\
\hline & $n^{(1)}$ & C.V.\% ${ }^{(2)}$ & Média & $\mathbf{n}$ & C.V.\% & Média \\
\hline & \multicolumn{6}{|c|}{$\mu \mathrm{g} \mathrm{g}^{-1}$ de C no solo } \\
\hline & \multicolumn{6}{|c|}{ F umigação } \\
\hline Não fumigado(3) & 4 & 2,19 & $77 \pm 2,1$ & 4 & 7,69 & $321 \pm 24$ \\
\hline \multirow[t]{2}{*}{ C microbiano } & $\begin{array}{l}4 \\
3 \\
2\end{array}$ & $\begin{array}{l}25,78 \\
19,08 \\
22,93\end{array}$ & $\begin{array}{l}247 \pm 62 \\
220 \pm 47 \\
205 \pm 46\end{array}$ & $\begin{array}{l}4 \\
3 \\
2\end{array}$ & $\begin{array}{l}29,68 \\
36,36 \\
21,75\end{array}$ & $\begin{array}{l}238 \pm 69 \\
238 \pm 98 \\
281 \pm 85\end{array}$ \\
\hline & \multicolumn{6}{|c|}{ Irradiação } \\
\hline Não irradiado(3) & 4 & 2,19 & $77 \pm 2,1$ & 4 & 7,69 & $321 \pm 24$ \\
\hline 2 minutos & $\begin{array}{l}4 \\
3 \\
2\end{array}$ & $\begin{array}{l}6,18 \\
6,41 \\
3,07\end{array}$ & $\begin{array}{l}269 \pm 16 \\
264 \pm 19 \\
255 \pm 11\end{array}$ & $\begin{array}{l}4 \\
3 \\
2\end{array}$ & $\begin{array}{l}50,32 \\
63,20 \\
80,80\end{array}$ & $\begin{array}{l}216 \pm 170 \\
209 \pm 150 \\
151 \pm 107\end{array}$ \\
\hline 5 minutos & $\begin{array}{l}4 \\
3 \\
2\end{array}$ & $\begin{array}{r}14,08 \\
16,14 \\
8,97\end{array}$ & $\begin{array}{l}374 \pm 52 \\
383 \pm 70 \\
249 \pm 43\end{array}$ & $\begin{array}{l}4 \\
3 \\
2\end{array}$ & $\begin{array}{l}28,39 \\
17,99 \\
20,95\end{array}$ & $\begin{array}{l}497 \pm 138 \\
555 \pm 113 \\
584 \pm 169\end{array}$ \\
\hline 10 minutos & $\begin{array}{l}4 \\
3 \\
2\end{array}$ & $\begin{array}{r}12,56 \\
13,36 \\
8,08\end{array}$ & $\begin{array}{l}650 \pm 80 \\
628 \pm 94 \\
583 \pm 65\end{array}$ & $\begin{array}{l}4 \\
3 \\
2\end{array}$ & $\begin{array}{l}18,24 \\
14,28 \\
26,41\end{array}$ & $\begin{array}{l}627 \pm 162 \\
699 \pm 113 \\
671 \pm 162\end{array}$ \\
\hline 15 minutos & $\begin{array}{l}4 \\
3 \\
2\end{array}$ & $\begin{array}{l}20,16 \\
18,77 \\
26,13\end{array}$ & $\begin{array}{l}544 \pm 107 \\
505 \pm 107 \\
510 \pm 185\end{array}$ & $\begin{array}{l}4 \\
3 \\
2\end{array}$ & $\begin{array}{l}38,08 \\
39,19 \\
49,18\end{array}$ & $\begin{array}{l}541 \pm 201 \\
584 \pm 259 \\
497 \pm 339\end{array}$ \\
\hline
\end{tabular}

(1) $\mathrm{n}=$ Número de amostras avaliadas. ${ }^{(2)} \mathrm{C} . \mathrm{V}$. = Coeficiente de variação. ${ }^{(3)}$ Carbono presente na amostra não fumigada ou não irradiada. 
A energia de 4,8 105 J foi aproximadamente a irradiação a que os solos foram expostos aos $5 \mathrm{~min}$ $(4,05105 \mathrm{~J})$, ao passo que, aos $10 \mathrm{~min}$, este valor aumentou em $100 \%(8,1105 \mathrm{~J})$. Entretanto, níveis el evados de energia, como os verificados aos $10 \mathrm{~min}$ de exposição, podem superestimar os valores de $C$ microbiano (Quadros 1 e2), pois estariam incluindo outra fonte de carbono que não a microbiana.

A limitação do uso de microondas para a determinação do $\mathrm{C}$ e $\mathrm{N}$ microbianos estaria relacionada com as possíveis quebras de ligações com carbono e nitrogênio presentes na matéria orgânica do solo, sendo a quebra promovida pela exposição a maiores quantidades de energia, superestimando, dessa forma, os valores da biomassa microbiana.

Monz et al. (1991) demonstraram que o tempo de 2 min (6,8 104 J ) não provocou a destruição da fração orgânica do solo, tendo Hendricks \& Pascoe (1988) recomendado tempo inferior a 5 min eenergia menor que2,1 105 J para que não ocorram possíveis quebras das ligações orgânicas do solo. Segundo Roberts \& Caserio (1965), os valores de 3,04 105 J , 3,16 105 J e 3,58 105 J seriam os níveis máximos para nãoocorrência de quebras das ligações simples de C-N, $\mathrm{C}-\mathrm{C}$ e C-O, respectivamente. Portanto, devem ser utilizados níveis próximos da faixa de 3,04 105 J para eliminação mais eficiente das populações bacterianas do solo, uma vez que as bactérias têm importante contribuição no equilíbrio dinâmico dos nutrientes do solo e contribuem com 20 a 30\% da biomassa microbiana do solo (Alexander, 1977).

Pelos resultados obtidos, exposição por 2 min a microondas poderá ser utilizada em substituição aos métodos tradicionais de fumigação-extração e, ou, fumigação-incubação. Contudo, ensaios deverãoser efetuados para verificar as margens de aplicabilidade do método apresentado para sol os com características químicas e físicas distintas e sob diferentes condições de manejo.

\section{CONCLUSÕES}

1. A exposição das amostras de solo a mi croondas, durante $2 \mathrm{~min}$, a 1,62 105 J , pode ser utilizada para estimar os valores de $\mathrm{C}$ e $\mathrm{N}$ microbianos de forma semelhante aos obtidos pela fumigação com clorofórmio para os procedimentos de extração e de incubação.

2. A irradiação reduziu os coeficientes de variação nas amostras de solo submetidas ao procedimento de extração, indicando ser o método irradiaçãoextração, em termos operacionais, o mais adequado para estimar o C e o N microbiano no solo.

\section{LITE RATURA CITADA}

ALEXANDER, M. Introduction to soil microbiology. 2.ed. New York, J ohn Wiley \& Sons, 1977. 467p.

BROOKES, P.C.; LANDMAN, A.; PRUDEN, G. \& J ENKINSON, D.S. Chloroform fumigation and therelease of soil nitrogen. A rapid direct extraction method to measure microbial biomass nitrogen in soil. Soil Biol. Biochem., 17:837-842, 1985.

DE-POLLI, H. \& GUERRA, J.G.M. Biomassa microbiana: perspecetivas para o uso e manejo do solo. In: ALVAREZV., H.V.; FONTES, L.E.F. \& FONTES, M.P. O solo nos grandes domínios morfoclimáticos do Brasil. Viçosa, Sociedade Brasileira de Ciência do Solo, 1996. p.552-564.

HENDRICKS, C.W. \& PASCOE, N. Soil microbial biomass estimates using $2.450 \mathrm{MHz}$ microwave irradiation. Plant Soil, 110:39-47, 1988.

JENKINSON, D.S. \& POWLSON, D.S. The effects of biocidal treatments on metabolism in soil. V. M ethod for measuring soil biomass. Soil Biol. Biochem., 8:209:213, 1976.

KASSIN, G.; MARTIN, J .P. \& HAIDER, K. Incorporation of a wide variety of organic substrate carbons into soil biomass as estimated by the fumigation procedure. Soil Sci. Soc. Am. J ., 45:1106-1112, 1981.

LOVELL, R.D.; J ARVIS, S.C. \& BARDGETT, R.D. Soil microbial biomass and activity in long-term grassland: effects of management changes. Soil Biol. Biochem., 27:969-975, 1995.

MONZ, C.A.; REUSS, D.E. \& ELLIOTT, E.T. Soil microbial biomass and nitrogen estimates using $2.450 \mathrm{MHZ}$ microwave irradiation or chloroform fumigation followed by direct extraction. Agric. E cosyst. Environ., 34:55-63, 1991.

PURI, G. \& BARRACLOUGH, D. Comparison of $2.450 \mathrm{MHz}$ microwave radiation and chloroform fumigation-extraction to estimate soil microbial biomass nitrogen using $15 \mathrm{~N}$ labelling. Soil Biol. Biochem., 25:521-522, 1993.

ROBERTS, J.D. \& CASERIO, C.M. Basic principles of organic chemistry. New York, Benjamin Cummings, 1965. 1315p.

SHIELDS, J .A.; PAUL, E.A. \& LOVE, W.E. Factors influencing the stability of labelled microbial materials in soil. Soil Biol. Biochem., 6:31-37, 1974.

SPARLING, G.P. \& WEST, A.W. A direct extraction method to estimatesoil microbial C: Calibration in situ using microbial respiration and ${ }^{14} \mathrm{C}$ labelled cells. Soil Biol. Biochem., 20:337-343, 1988.

STOTZKY, G. Microbial respiration. In: BLACK, C.A., eds. Methods of soil analysis. Part 2. Madison, American Society of Agronomy, 1965. p.1550-1572.

TEDESCO, M.J .; BOHNEM, H.; GIANELLO, C.; BISSANI, C.A. \& VOLKWEISS, S.J. Análise de solo, plantas e outros materiais. 2.ed. Porto Alegre, Universidade Federal do Rio Grande do Sul, 1995. 174p. (Boletin Técnico, 5) 
VANCE, E.D.; BROOKES, P.C. \& JENKINSON, D.S. An extraction method for measuring soil microbial biomass $C$. Soil Biol. Biochem., 19:703-707, 1987.

VELA, G.R.; WU, J .F. \& SMITH, D. Effect of 2450 MHz microwave radiation on some soil microrganisms in situ. Soil Sci., 121:44-51, 1976.
ZAGAL, E. Effects of microwave radiation on carbon and nitrogen mineralization in soil. Soil Biol. Biochem., 21:603-605, 1989.

WAINWRIGHT, M.; KILLHAM, K. \& DIPROSE, M.F. Effects of $2.450 \mathrm{MHz}$ microwave radiation on nitrification and S-oxidation in soil. Soil Biol. Biochem., 12:489-493, 1980. 